\title{
Thermal decomposition and mass spectra of mixed ligand copper(II) complexes of 1,10-phenanthroline and coumarin derivatives
}

\author{
G. J. Kharadi
}

Received: 30 December 2010/Accepted: 17 May 2011/Published online: 28 May 2011

(C) The Author(s) 2011. This article is published with open access at Springerlink.com

\begin{abstract}
Four copper(II) new mix ligand complexes of the coumarin derivative $\left(\mathrm{A}^{1}=7\right.$-hydroxy-10,11-dihydroindeno[5,4-c]chromen-6(9H)-one, $\mathrm{A}^{2}=2$-bromo-7hydroxy-10,11- dihydroindeno[5,4-c]chromen-6(9H)-one, $\mathrm{A}^{3}=7$-hydroxy-4-methoxy-10,11-dihydroindeno[5,4-c]ch romen-6(9H)-one, and $\mathrm{A}^{4}=5$-hydroxy-8,9-dihydrobenzo[f]in deno[5,4-c]chromen-4(7H)-one) and 1,10-Phenanthroline have been synthesized. The structural interpretations were confirmed from elemental analyses, magnetic susceptibility and FAB mass spectral, as well as from IR spectral studies. From the analytical, spectroscopic, and thermal data, the stoichiometry of the mentioned complexes was found to be 1:1:1 (coumarin ligand:copper metal:1,10-Phenanthroline). The thermal stabilities of these complexes were studied by thermogravimetric (TG/DTG) and the decomposition steps of these four complexes are investigated. Kinetic parameters such as order of reaction $(n)$ and the energy of activation $\left(E_{\mathrm{a}}\right)$ were calculated using Freeman-Carroll method. The pre-exponential factor $(A)$, the activation entropy $\left(S^{*}\right)$, the activation enthalpy $\left(H^{*}\right)$, and the free energy of activation $\left(G^{*}\right)$ were calculated using Horowitz-Matzger equations. Based on the $E_{\mathrm{a}}$ values, the thermal stabilities of complexes in the decreasing order are $\mathrm{Cu}$ (II)-2 > Cu(II)-3 > Cu(II)-4 > Cu(II)-1.
\end{abstract}

Keywords Thermal study · Mass spectra - Copper(II) · 1,10-Phenanthroline $\cdot$ Coumarin derivatives

Electronic supplementary material The online version of this article (doi:10.1007/s10973-011-1671-x) contains supplementary material, which is available to authorized users.

G. J. Kharadi $(\bowtie)$

Department of Chemistry, Shri R. R. Lalan College, K. S. K. V. Kachchh University, Bhuj, Gujarat, India

e-mail: gaurangkharadi@yahoo.com; drkharadi84@gmail.com

\author{
Abbreviation \\ $\mathrm{Ph}$ \\ $\mathrm{A}^{n}$ \\ 1,10-phenanthroline \\ c]chromen-6(9H)-one \\ $\mathrm{A}^{2}$ 2-bromo-7-hydroxy-10,11- \\ $\mathrm{A}^{3}$ 7-hydroxy-4-methoxy-10,11- \\ $\mathrm{A}^{4}$ \\ dihydroindeno[5,4-c]chromen-6(9H)-one \\ 5-hydroxy-8,9-dihydrobenzo[f]indeno[5,4- \\ c]chromen-4(7H)-one \\ D. D. Water Double distilled water \\ $\mathrm{Cu}(\mathrm{II})-n$ \\ $\mathrm{Cu}(\mathrm{II})-1, \mathrm{Cu}(\mathrm{II})-2, \mathrm{Cu}(\mathrm{II})-3, \mathrm{Cu}(\mathrm{II})-4$ \\ $\mathrm{Cu}(\mathrm{II})-1$ \\ $\left[\mathrm{Cu}\left(\mathrm{A}^{1}\right)(\mathrm{Ph})(\mathrm{OH})\left(\mathrm{H}_{2} \mathrm{O}\right)\right] \cdot 3 \mathrm{H}_{2} \mathrm{O}$ \\ $\mathrm{Cu}(\mathrm{II})-2$ \\ $\left[\mathrm{Cu}\left(\mathrm{A}^{2}\right)(\mathrm{Ph})(\mathrm{OH})\left(\mathrm{H}_{2} \mathrm{O}\right)\right] \cdot 2 \mathrm{H}_{2} \mathrm{O}$ \\ $\mathrm{Cu}(\mathrm{II})-3$ \\ $\mathrm{Cu}(\mathrm{II})-4$ \\ B.M. \\ $\left[\mathrm{Cu}\left(\mathrm{A}^{3}\right)(\mathrm{Ph})(\mathrm{OH})\left(\mathrm{H}_{2} \mathrm{O}\right)\right] \cdot \mathrm{H}_{2} \mathrm{O}$ \\ $\left[\mathrm{Cu}\left(\mathrm{A}^{4}\right)(\mathrm{Ph})(\mathrm{OH})\left(\mathrm{H}_{2} \mathrm{O}\right)\right] \cdot \mathrm{H}_{2} \mathrm{O}$ \\ Bohr magneton
}

\section{Introduction}

The thermal analysis techniques were extensively applied in studying of the thermal behavior of metal complexes [1]. In studies on the physical and chemical properties and the structures of solid complexes of transition metal ions with organic ligands, it is customary to investigate the thermal decomposition of these complexes so as to obtain useful data on the metal-ligand bonds [2-4] and stability trends. The thermal investigations on some derivatives of amines [5], sulfonamides [6], substituted thiourea salts [7], and complexes of bidentate ligands and others [8-13], have already been published. 
The copper(II) complexes were characterized by different analytical and spectral methods. The thermal behaviors of the obtained complexes were also investigated. The thermal analysis techniques, such as thermogravimetry (TG), differential thermal analysis (DTA), and differential scanning calorimetry (DSC), were widely applied in studying the thermal behavior and the structure of metal complexes [14-25]. The results allowed us to acquire information concerning the structure of these compounds, including their thermal behavior and decomposition. Thermal analysis let us also to evaluate the presence of crystallization water molecules in the complexes and to determine the endothermic and/or exothermic effects connected with such processes as: dehydration, melting, crystallization, and decomposition. In view of the importance of copper(II) compounds and our interest in the chemistry of coordination compounds involving chelating coumarin base [26, 27], we report here the synthesis, characterization, and reactivity of copper(II) complexes containing coumarin base ligands with $\mathrm{O}, \mathrm{N}, \mathrm{N}, \mathrm{O}$, donor set, etc.

\section{Experimental}

\section{Materials}

All reagents were of analytical-reagent (AR) grade and were used without further purification. Solvents employed were purified by standard procedures prior to use [28]. 1,10-phenanthroline was purchased from Aldrich. Salicylaldehyde, ethyl acetoacetate, piperidine, chloroform, hexane, bromine, pyridine, toluene, cyclopentanone, cyclohexanone, $\alpha$-tetralone, dimethyl formamide, and $\mathrm{Cu}$ $\left(\mathrm{NO}_{3}\right)_{2} \cdot 3 \mathrm{H}_{2} \mathrm{O}$ were purchased from the E. Merck (India) Limited, Mumbai. Acetic acid and EDTA were purchased from Sigma Chemical Co., India.

\section{Instruments}

Elemental analyses $(\mathrm{C}, \mathrm{H}, \mathrm{N})$ were analyzed with the PerkinElmer, USA 2400-II CHN analyzer. FT-IR spectra (4000-400 $\mathrm{cm}^{-1}$ ) were recorded on Nicolet-400D spectrophotometer using $\mathrm{KBr}$ pellets. The magnetic moments were obtained by the Gouy's method using mercury tetrathiocyanato cobaltate(II) as a calibrant $(g=16.44 \times$ $10^{-6}$ c.g.s. units at $20^{\circ} \mathrm{C}$ ). Diamagnetic corrections were made using Pascal's constant. The FAB mass spectrum of the complex was recorded at SAIF, CDRI, Lucknow with JEOL SX-102/DA-6000 mass spectrometer. A simultaneous TG/DTG had been obtained by a model 5000/2960 SDT, TA Instruments, USA. The experiments were performed in $\mathrm{N}_{2}$ atmosphere at a heating rate of $10{ }^{\circ} \mathrm{C} \mathrm{min}-1$ in the temperature range $50-800{ }^{\circ} \mathrm{C}$, using $\mathrm{Al}_{2} \mathrm{O}_{3}$ crucible. The sample sizes are ranged in mass from 4.5 to $10 \mathrm{mg}$.

\section{Synthesis of ligands $\left(\mathrm{A}^{n}\right)(n=1-4)$}

The coumarin base ligands $\left(\mathrm{A}^{n}\right)$ (where $n=1-4$ ) were synthesized according to the procedure described in the literature [29].

\section{Synthesis of complexes $(\mathrm{Cu}(\mathrm{II})-n)(n=1-4)$}

A water solution $(100 \mathrm{~mL})$ of $\mathrm{Cu}\left(\mathrm{NO}_{3}\right)_{2} \cdot 3 \mathrm{H}_{2} \mathrm{O}(10 \mathrm{mmol})$ was added to dimethyl formamide solution $(100 \mathrm{~mL})$ of ligand $\left(\mathrm{A}^{n}\right)(10 \mathrm{mmol})$, followed by addition of 1,10-phenanthroline $(10 \mathrm{mmol})$ in ethanol; the $\mathrm{pH}$ was adjusted to $4.5-6.0$ by dropwise addition of $25 \% \mathrm{NaOH}$ solution in water. The mixture was heated in a water bath for $3 \mathrm{~h}$ at $70{ }^{\circ} \mathrm{C}$. The mixture was kept overnight at room temperature. The colored crystals obtained were washed with water, methanol, and finally with diethyl ether and dried in air.

\section{Results and discussion}

The following compounds have been studies:

\begin{tabular}{ll}
\hline $\mathrm{Cu}$ (II)-1 or $\mathrm{C}_{28} \mathrm{H}_{28} \mathrm{CuN}_{2} \mathrm{O}_{8}$ & (A) \\
$\mathrm{Cu}(\mathrm{II})-2$ or $\mathrm{C}_{28} \mathrm{H}_{25} \mathrm{BrCuN}_{2} \mathrm{O}_{7}$ & (B) \\
$\mathrm{Cu}$ (II)-3 or $\mathrm{C}_{29} \mathrm{H}_{26} \mathrm{CuN}_{2} \mathrm{O}_{7}$ & (C) \\
$\mathrm{Cu}(\mathrm{II})-4$ or $\mathrm{C}_{32} \mathrm{H}_{26} \mathrm{CuN}_{2} \mathrm{O}_{6}$ & (D) \\
\hline
\end{tabular}

Color, elemental analysis, and melting point of the complexes are presented in Table 1. The complexes are colored and stable in air. They are insoluble in water and in most organic solvents but soluble in DMSO.

\section{IR spectra}

Interpretation of infrared spectra of free $\mathrm{A}^{n}$ ligand and copper(II) complexes gave an idea about the mode of chelation and follow-up of the effect of coordination of metal ions on the vibration motions of free ligand. The IR spectra of the free ligand and its metal chelates were carried out within the mid-IR range $4000-400 \mathrm{~cm}^{-1}$. The IR spectrum of the free ligand shows a very strong band at $\sim 3460 \mathrm{~cm}^{-1}$, which can be attributed to the aryl $-\mathrm{OH}$ 
Table 1 Color, elemental analysis and melting point of the complexes

\begin{tabular}{lllllll}
\hline Complexes & Color & \multicolumn{2}{l}{ Found (calc. \%) } & \multicolumn{2}{c}{ Dec. point $/{ }^{\circ} \mathrm{C}$} \\
\cline { 3 - 6 } & & $\mathrm{C}$ & $\mathrm{H}$ & $\mathrm{N}$ & $\mathrm{Cu}$ \\
\hline $\mathrm{Cu}(\mathrm{II})-1$ & Dark green & $57.46(57.58)$ & $4.81(4.83)$ & $4.76(4.80)$ & $10.52(10.88)$ & $>350$ \\
$\mathrm{Cu}(\mathrm{II})-2$ & Dark green & $52.09(52.14)$ & $3.82(3.91)$ & $4.31(4.34)$ & $9.77(9.85)$ & $>350$ \\
$\mathrm{Cu}(\mathrm{II})-3$ & Dark green & $6.14(60.25)$ & $4.44(4.53)$ & $4.79(4.85)$ & $10.85(10.99)$ & $>350$ \\
$\mathrm{Cu}(\mathrm{II})-4$ & Dark green & $64.12(64.26)$ & $4.25(4.38)$ & $4.65(4.68)$ & $10.58(10.62)$ & $>350$ \\
\hline
\end{tabular}

group [30]. This band is shifted to lower wave numbers at $\sim 3445$ and $\sim 3405 \mathrm{~cm}^{-1}$ in case of other metal complexes, respectively, but this band was absent in case of copper(II) complex which was assigned to the involvement of $-\mathrm{OH}$ group in the chelating. The shared aryl $-\mathrm{OH}$ group in coordination is confirmed by the hypochromic effect (decrease in intensity) of the $v(\mathrm{C}-\mathrm{O})$ stretching band observed at $\sim 1250 \mathrm{~cm}^{-1}$ in the free ligand and the complexes due to substituent's or interactions with the molecular environment [30]. The IR spectrum of the free ligand revealed a very strong-to-strong bands at 1633 and $1598 \mathrm{~cm}^{-1}$ due to $v(\mathrm{C}=\mathrm{N})$ of the 1,10 -phenanthroline. This band is shifted to lower frequencies $\left(30-38 \mathrm{~cm}^{-1}\right)$ in the complexes assigned that it has been affected upon complexation via metal ions. In the $500-400 \mathrm{~cm}^{-1}$ region, the spectra of all complexes have a detected bands observed at $\sim 550$ and $468 \mathrm{~cm}^{-1}$ [31], which can be assigned to the $v(\mathrm{Cu}-\mathrm{O})$ and $v(\mathrm{Cu}-\mathrm{N})$ stretching vibrations, respectively. Therefore, the IR spectra indicate that $\mathrm{A}^{n}$ behaves as a uninegative bidentate and the coordination sites being ArOH of coumarin derivative ligand and $\mathrm{C}=\mathrm{N}$ of the 1,10 phenanthroline.

\section{Mass spectra}

Mass spectrometric techniques offer comparative advantages for speed and productivity for pharmaceutical analysis [32]. The recorded mass spectra (Fig. 1) and the molecular ion peak for the complex $\mathrm{Cu}(\mathrm{II})-n$ have been used to confirm the molecular formula. The fragmentation pattern is given in supplementary material.

\section{Cu(II)-1}

The first peak at $m / e 529$ represents the molecular ion peak of the complex. The primary fragmentation of the complex takes place due to the loss of $-\mathrm{OH}_{2}$ and $-\mathrm{OH}$ group from the species (a) to give species (b) with peak at $m / e$ 494. The species (b) further degrades with the subsequent loss of $-\mathrm{C}_{3} \mathrm{H}_{5}$ species forming species (C) with their peak at $m / e$ 452. The species (c) further degrades with the subsequent loss of $-\mathrm{CO}_{2}$ species forming species (d) with their peak observed at $m / e 408$ represents the stable species with 99.6\% abundance. The species (d) further degrades with the subsequent loss of $-\mathrm{C}_{6} \mathrm{H}_{4}$ species forming species (e) with their peak at $m / e$ 305. The species (e) further degrades with the subsequent loss of $-\mathrm{C}_{6} \mathrm{H}_{5}$ species forming species (f) with peak at $m / e$ 227. The species (f) further degrades with the subsequent loss of $-\mathrm{C}_{6} \mathrm{H}_{5}$ species forming species ( $\mathrm{g}$ ) with peak at $m / e \quad 156$ and species ( $g$ ) further degrades with the subsequent loss of $-\mathrm{C}_{5} \mathrm{H}_{3} \mathrm{~N}$ species forming species (h) with peak at $m / e 78$.

\section{Cu(II)-2}

The first peak at $m / e 607$ represents the molecular ion peak of the complex. The primary fragmentation of the complex takes place due to the loss of - $\mathrm{OH}$ group from the species (a) to give species (b) with peak at $m / e$ 590. The species (b) further degrades with the subsequent loss of $-\mathrm{Br}$ species forming species (C) with their peak at $m / e$ 511. The species (c) further degrades with the subsequent loss of $-\mathrm{C}_{4} \mathrm{H}_{3}$ species forming species (d) with their peak at $m / e$ 460. The species (d) further degrades with the subsequent loss of $-\mathrm{C}_{3} \mathrm{H}_{6}$ species forming species (e) with their peak at $m / e$ 418. The species (e) further degrades with the subsequent loss of $-\mathrm{C}_{2} \mathrm{H}_{2}$ species forming species (f) with peak observed at $m / e 392$ represents the stable species with $99.2 \%$ abundance. The species (f) further degrades with the subsequent loss of $-\mathrm{C}_{4} \mathrm{H}_{3}$ species forming species $(\mathrm{g})$ with peak at $m / e$ 327. The species (g) further degrades with the subsequent loss of $-\mathrm{OH}_{2}$ species forming species (h) with peak at $m / e 308$ and species (h) further degrades with the subsequent loss of $-\mathrm{C}_{10} \mathrm{H}_{6} \mathrm{~N}_{2}$ species forming species (I) with peak at $m / e 154$.

\section{Cu(II)-3}

The first peak at $m / e 559$ represents the molecular ion peak of the complex. The primary fragmentation of the complex 
Fig. 1 Mass spectra of $\mathrm{Cu}(\mathrm{II})$ $n$ complexes
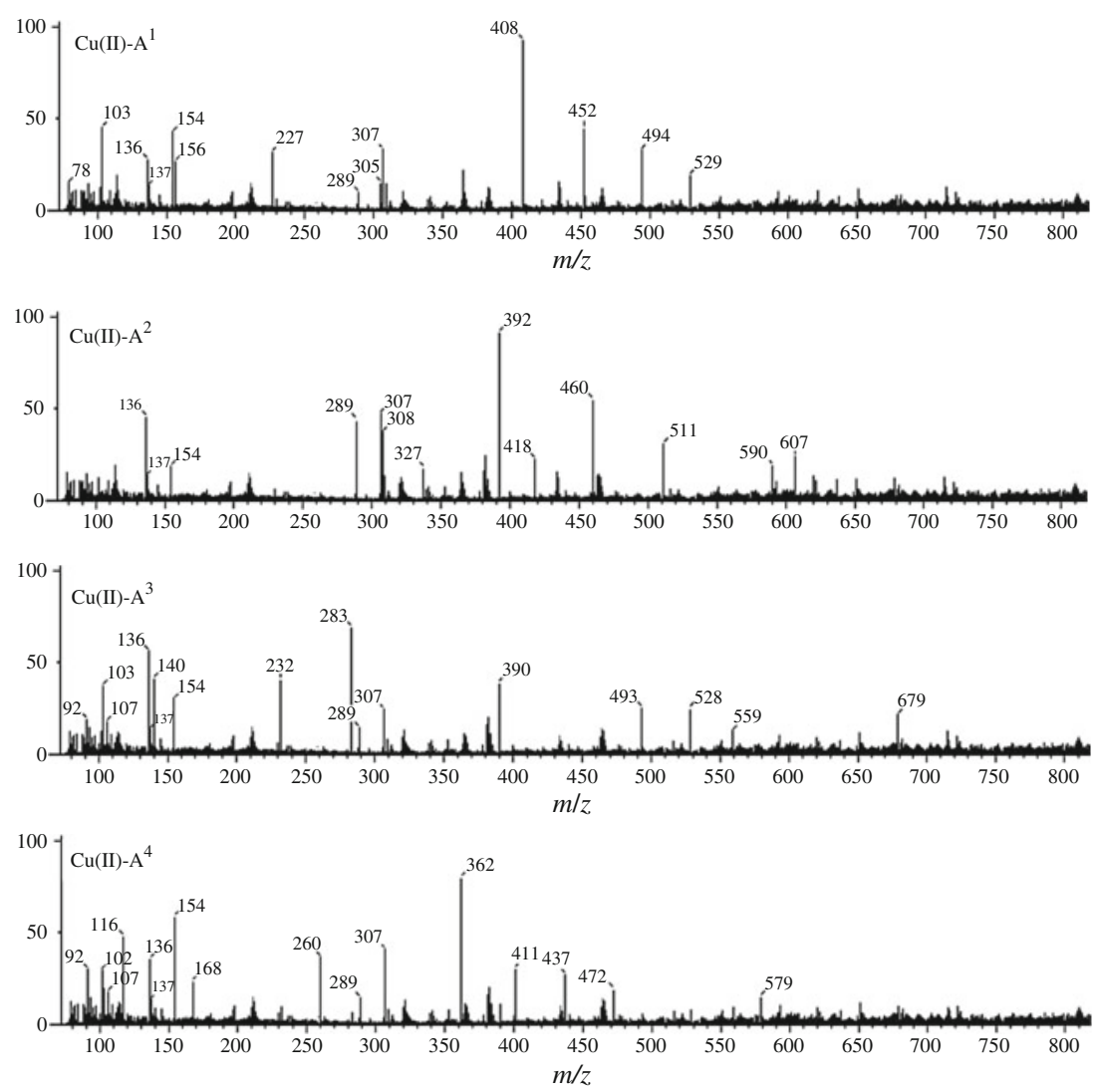

takes place due to the loss of $-\mathrm{OCH}_{3}$ group from the species (a) to give species (b) with peak at $m / e$ 528. The species (b) further degrades with the subsequent loss of $-\mathrm{OH}_{2}$ and $-\mathrm{OH}$ species forming species (C) with their peak at $m / e$ 493. The species (c) further degrades with the subsequent loss of $-\mathrm{C}_{7} \mathrm{H}_{5} \mathrm{~N}$ species forming species (d) with their peak at $m / e$ 390. The species (d) further degrades with the subsequent loss of $-\mathrm{C}_{7} \mathrm{H}_{7} \mathrm{O}$ species forming species (e) with their peak observed at $m / e 280$ represents the stable species with $82.4 \%$ abundance. The species (e) further degrades with the subsequent loss of $-\mathrm{C}_{4} \mathrm{H}_{4}$ species forming species (f) with peak at $m / e$ 232. The species (f) further degrades with the subsequent loss of $-\mathrm{C}_{5} \mathrm{H}_{4} \mathrm{O}_{2}$ species forming species (g) with peak at $m / e 140$.

\section{$\mathrm{Cu}(\mathrm{II})-4$}

The first peak at $m / e 579$ represents the molecular ion peak of the complex. The primary fragmentation of the complex takes place due to the loss of $-\mathrm{C}_{7} \mathrm{H}_{7} \mathrm{O}$ group from the species (a) to give species (b) with peak at $m / e$ 472. The species (b) further degrades with the subsequent loss of $-\mathrm{OH}_{2}$ and $-\mathrm{OH}$ species forming species (C) with their peak at $m / e$ 437. The species (c) further degrades with the subsequent loss of $-\mathrm{C}_{2} \mathrm{H}_{2}$ species forming species (d) with their peak at $m / e$ 411. The species (d) further degrades with the subsequent loss of $-\mathrm{C}_{4} \mathrm{H}_{6}$ species forming species (e) with their peak observed at $m / e 362$ represents the stable species with $99.6 \%$ abundance. The species (e) further degrades with the subsequent loss of $-\mathrm{C}_{8} \mathrm{H}_{6}$ species forming species (f) with peak at $m / e$ 260. The species (f) further degrades with the subsequent loss of $-\mathrm{C}_{5} \mathrm{H}_{4} \mathrm{O}_{2}$ species forming species $(\mathrm{g})$ with peak at $\mathrm{m} / \mathrm{e} 168$ and species $(\mathrm{g})$ further degrades with the subsequent loss of $-\mathrm{C}_{4} \mathrm{H}_{4}$ species forming species (h) with peak at $m / e 116$.

Electronic spectra and magnetic moments

Copper(II) complexes ( $\mathrm{d}^{9}$ system) are known for their varieties of structures due to their various coordination numbers. Six coordinated copper(II) complexes possesses distorted octahedral geometry. The spectra of copper complexes are very difficult to assign even with relatively simple ligands because of the breadth of absorption band even at low temperature. The different coordination number having wide range of geometry. Generally for square pyramidal copper(II) complexes, bands observed in the region $9000-10000,11500-16000$, and 15000-19000 $\mathrm{cm}^{-1}$ have been ascribed to the transition ${ }^{2} \mathrm{~B}_{1} \rightarrow{ }^{2} \mathrm{~A}_{1}$, ${ }^{2} \mathrm{~B}_{1} \rightarrow{ }^{2} \mathrm{~B}_{2}$, and ${ }^{2} \mathrm{~B}_{1} \rightarrow{ }^{2} \mathrm{E}$, respectively. The diffuse reflectance spectra of square pyramidal copper(II) 
complexes $\mathrm{Cu}(\mathrm{II})-n$ have been taken in solid state. The spectra of copper(II) complexes exhibit a three band observed in the 9050, 13500, and $16600 \mathrm{~cm}^{-1}$ [33-35]. These bands are characteristic of copper(II) $d$ - $d$ transition in tetragonal field in which copper(II) atom is in distorted square pyramidal coordination environment. The copper(II)- $\mathrm{d}^{9}$ system and its compounds are expected to have magnetic moment close to be spin only value 1.73 B.M. Generally the magnetic moments of copper(II) in any of its geometry lies around 1.8 B.M. at room temperature. The magnetic moment value of copper(II) complexes obtained in the range of 1.76-1.92 B.M., which are close to the spinonly values expected in $S=1 / 2$ system (1.73 B.M.) and may be indicative of five coordinating copper(II) complexes and consistent with the presence of single unpaired electron $[36,37]$.

Calculation of activation thermodynamic parameters of the decomposed complexes

Each decomposition process follows the trend

Solid-1 $\stackrel{\text { heat }}{\longrightarrow}$ Solid- $2+$ Gas

This process comprises several stages. The method reported by Freeman-Carroll [38] has been adopted. Plots of $[\Delta \log (\mathrm{d} w / \mathrm{d} t) / \Delta \log w r]$ versus $[\Delta(1 / T) / \Delta \log w r]$ were linear for all of the decomposition steps. The energy of activation $E_{\mathrm{a}}$ was calculated from the slopes of these plots for a particular stage and the order of reactions $(n)$ determined from the intercept, showing first order reaction over the entire range of decomposition for all of the complexes. A typical plot for the thermal degradation of $\mathrm{Cu}(\mathrm{II})-1$ is shown in Fig. 2.

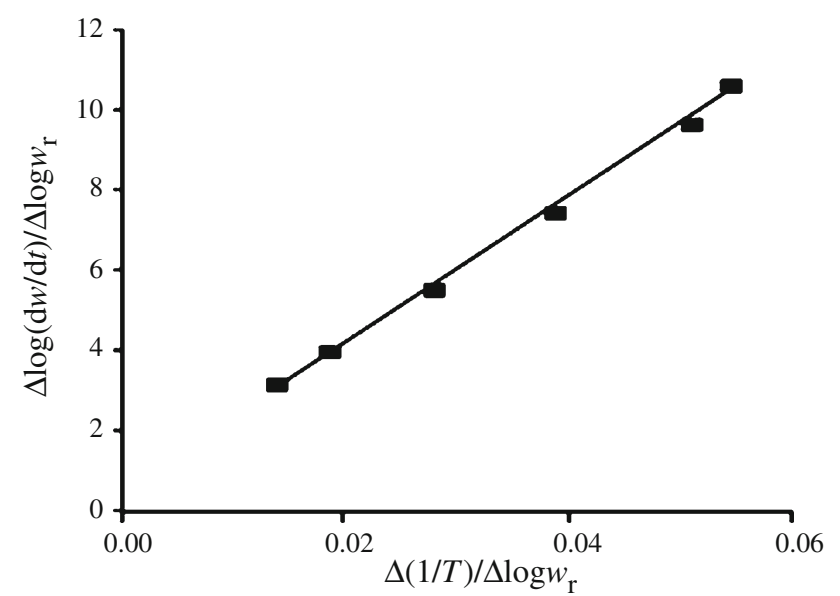

Fig. 2 Freeman-Carroll plot for thermal degradation of $\mathrm{Cu}(\mathrm{II})-1$ complex
The thermal behavior of the prepared complexes

In the following paragraphs, the thermal behavior of the synthesized complexes, characterized on the basis of TG/ DTG and DTA methods, is described.

\section{Cu(II)-1}

TG/DTG and DTA curves of the complex $\mathrm{Cu}(\mathrm{II})-1$ are represented in Figs. 3 and 4, respectively. The thermal decomposition of the complex $\mathrm{Cu}$ (II)-1 take place in three stages. The thermal dehydration of this complex takes place in a single step between 40 and $190{ }^{\circ} \mathrm{C}$, with a mass loss is $4.75 \%$ (calc. $4.84 \%$ ). The maximum rate of mass loss is indicated by the DTG peak at $185^{\circ} \mathrm{C}$. Three mole of lattice water molecules and (one mole water + one mole hydroxy) of coordinated molecules are removed in this stage of dehydration. The total loss of two water and one hydroxyl molecules is a first-order reaction and the value of the energy of activation for the dehydration process is

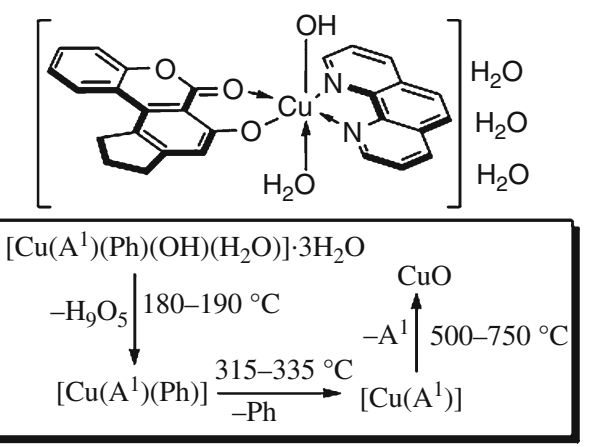

Fig. 3 Final structure and thermal scheme of $\mathrm{Cu}(\mathrm{II})-1$ complex

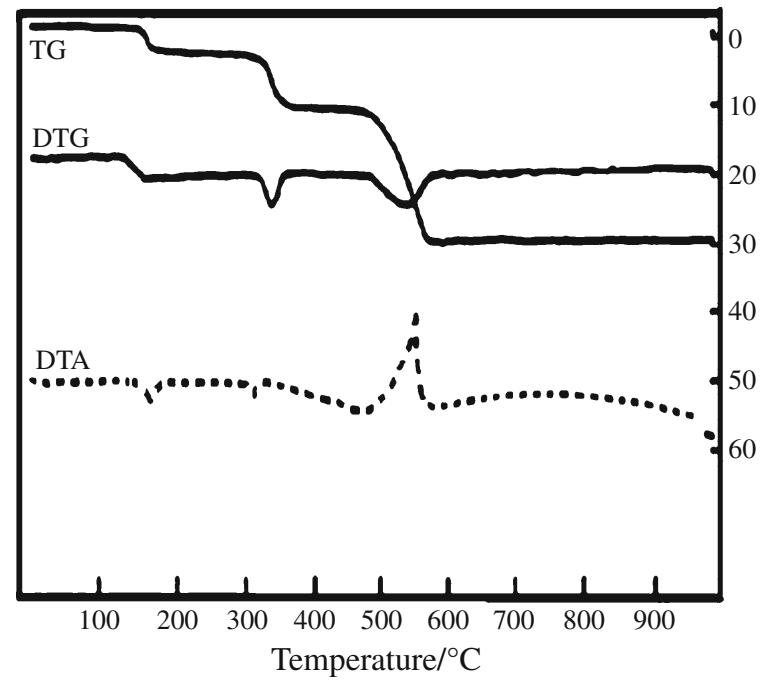

Fig. 4 TG/DTG and DTA curves of $\mathrm{Cu}(\mathrm{II})-1$ complex 
$3.16 \mathrm{~kJ} \mathrm{~mol}^{-1}$. The second stage, which occurs in the temperature range of $315-335^{\circ} \mathrm{C}$ with a DTG peak observed at $325^{\circ} \mathrm{C}$, corresponds to the decomposition of the $\mathrm{Ph}$ ligand. The observed mass loss is $40.67 \%$ (calc. 44.63). The third stage is related to the decomposition of $\mathrm{A}^{1}$ ligand in the temperature range of $500-750{ }^{\circ} \mathrm{C}$ with wellseparated DTG peaks at $550{ }^{\circ} \mathrm{C}$, accompanied by a mass loss of $44.92 \%$ (calc. 44.60). The overall mass loss observed is $90.34 \%$ as compared to the theoretical value $90.43 \%$. The end product estimated as $\mathrm{CuO}$, has the observed mass of $9.49 \%$ compared to the calculated value of $9.55 \%$.

\section{Cu(II)-2}

The $\mathrm{Cu}(\mathrm{II})-2$ complex undergoes decomposition in three stages (Figs. 5 and 6). The thermal dehydration of this complex takes place in a single step between 40 and $200{ }^{\circ} \mathrm{C}$, with a mass loss of $9.67 \%$ (calc. 9.41). The maximum rate of mass loss is indicated by the DTG $190{ }^{\circ} \mathrm{C}$. Two lattice and (one mole water + one mole hydroxy) are removed in
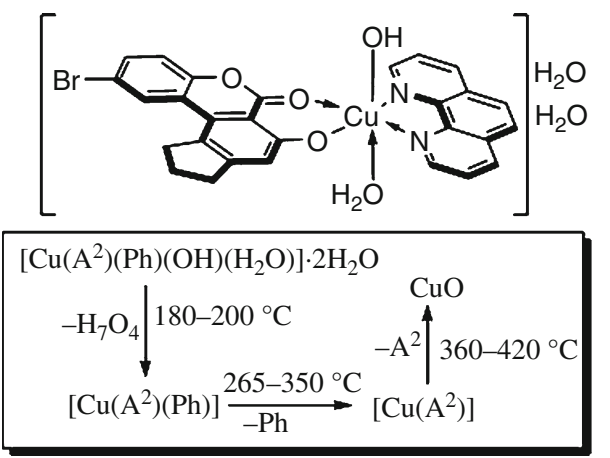

Fig. 5 Final structure and thermal scheme of $\mathrm{Cu}(\mathrm{II})-2$ complex

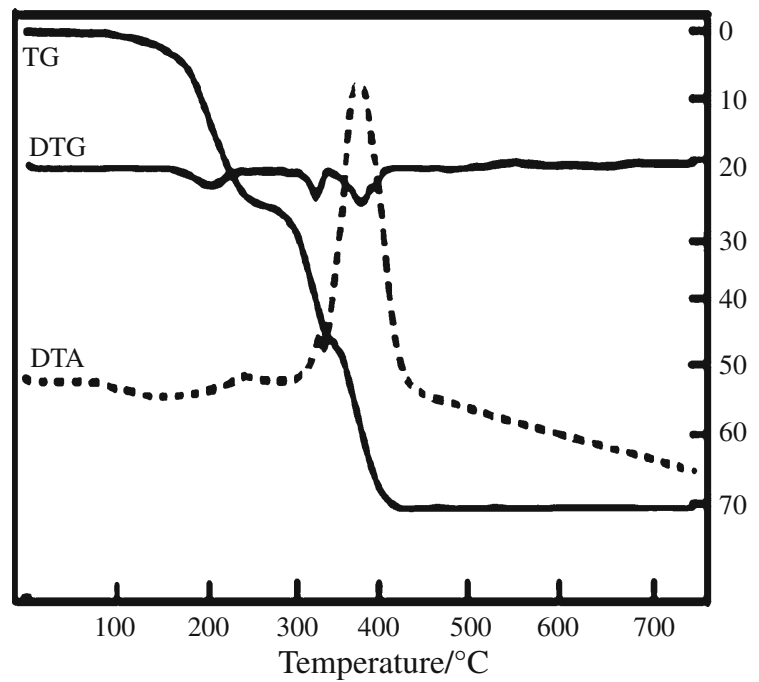

Fig. 6 TG/DTG and DTA curves of $\mathrm{Cu}(\mathrm{II})-2$ complex this stage of dehydration. The total loss of two lattice and (one mole water + one mole hydroxy) of coordinated water molecules is a first-order reaction and the value of energy of activation for the dehydration process is $12.28 \mathrm{~kJ} \mathrm{~mol}^{-1}$. The second stage occurs in the temperature range $265-350{ }^{\circ} \mathrm{C}$, with the mass loss $(39.40 \%)$ is due to the removal of $\mathrm{Ph}$ ligand from the complex (calc. $39.81 \%$ ). The DTG peak corresponding to this stage is found at $330{ }^{\circ} \mathrm{C}$. The third stage is related to the decomposition of $\mathrm{A}^{2}$ ligand, taking place in the temperature range $360-420{ }^{\circ} \mathrm{C}$ with a DTG peak at $400{ }^{\circ} \mathrm{C}$ and being accompanied by a mass loss of $41.78 \%$ (calc. $41.49 \%$ ). The overall mass losses are observed to be $90.85 \%$, which is in very good agreement with the calculated value of $90.71 \%$. The final residue, estimated as $\mathrm{CuO}$ has the observed mass $9.12 \%$ as against the calculated value of $9.27 \%$.

\section{Cu(II)-3}

Figures 7 and 8 in this complex takes place in a single step between 40 and $230{ }^{\circ} \mathrm{C}$, with a mass loss of $4.53 \%$ (calc.
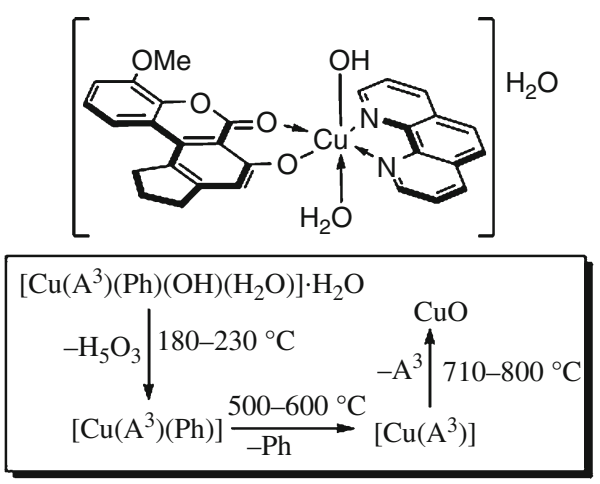

Fig. 7 Final structure and thermal scheme of $\mathrm{Cu}(\mathrm{II})-3$ complex

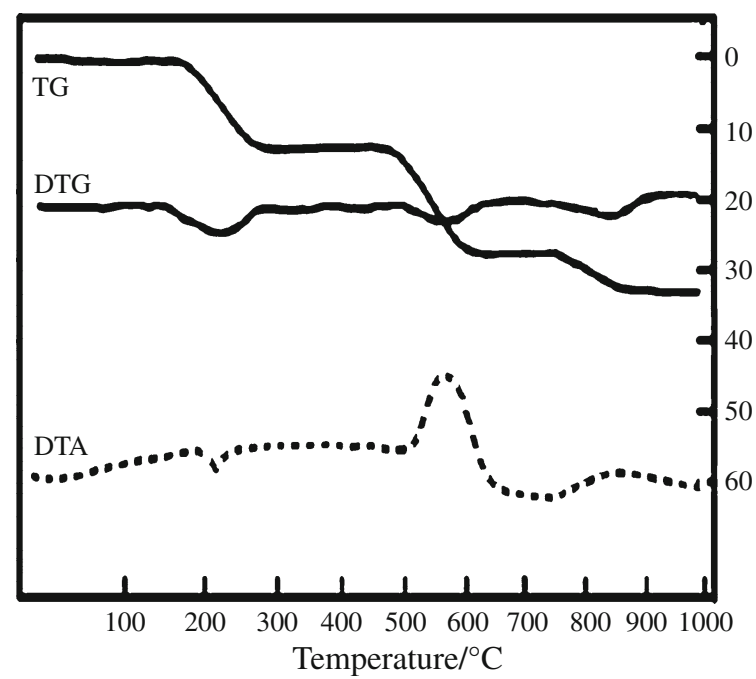

Fig. 8 TG/DTG and DTA curves of $\mathrm{Cu}(\mathrm{II})-3$ complex 

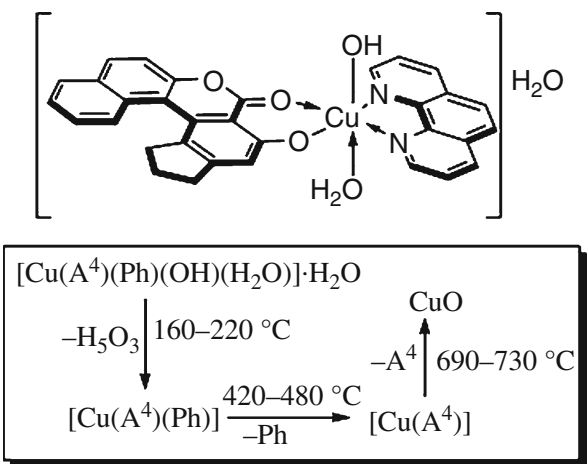

Fig. 9 Final structure and thermal scheme of $\mathrm{Cu}(\mathrm{II})-4$ complex

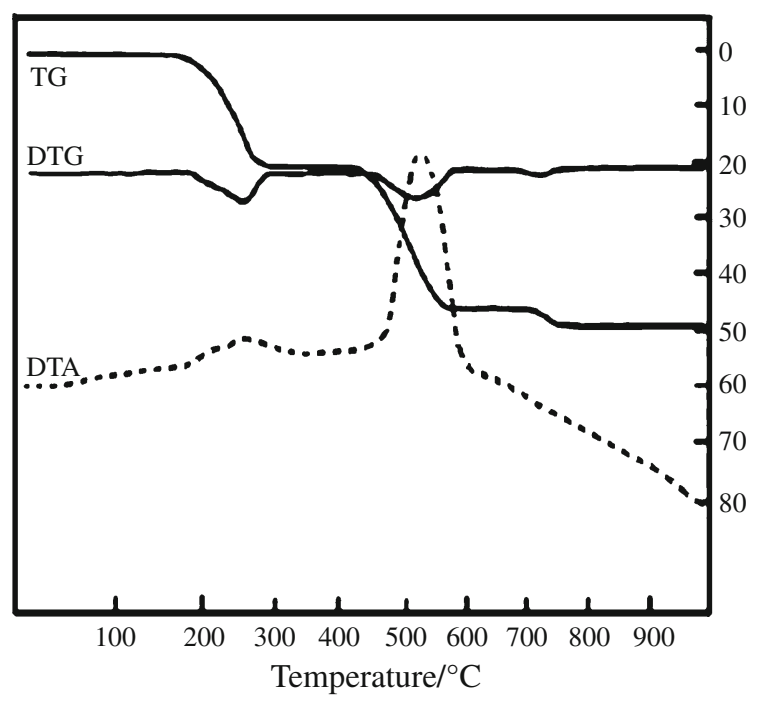

Fig. 10 TG/DTG and DTA curves of $\mathrm{Cu}(\mathrm{II})-4$ complex

$4.54 \%$ ). The maximum rate of mass loss is indicated by the DTG $220{ }^{\circ} \mathrm{C}$. One lattice and (one mole water + one mole hydroxy) are removed in this stage of dehydration. It was found that the loss of one lattice and (one mole water + one mole hydroxy) is a first-order reaction, and the value of the energy of activation for the dehydration process is $5.25 \mathrm{~kJ} \mathrm{~mol}^{-1}$. After dehydration, the crystal structure of the complex is distorted. In the second stage between 500 and $600{ }^{\circ} \mathrm{C}$, the $\mathrm{Ph}$ ligand degrades as one maximum in the DTG curve at $570{ }^{\circ} \mathrm{C}$ with a mass loss of $38.45 \%$ (calc. $38.50 \%$ ). The third stage, which occurs in the temperature range of $710-800{ }^{\circ} \mathrm{C}$ with DTG peak observed at $810^{\circ} \mathrm{C}$, corresponds to the decomposition of $\mathrm{A}^{3}$ ligand. The observed mass loss $(48.08 \%)$ is coinciding with the calculated value of $48.22 \%$. The overall mass losses are observed to be $91.06 \%$, which is in very good agreement with the calculated value of $91.26 \%$. The final residue, estimated as $\mathrm{CuO}$, has the observed mass $8.67 \%$ as against the calculated value of $8.90 \%$.

\section{Cu(II)-4}

The thermal decomposition of the complex $\mathrm{Cu}(\mathrm{II})-4$ undergoes in three stages (Figs. 9 and 10). The first stage is related to the liberation of one lattice and (one mole water + one mole hydroxy) are removed in this stage of dehydration. It was found that the loss of one lattice and (one mole water + one mole hydroxy) is a first-order reaction, and the value of the energy of activation for the dehydration process is $4.01 \mathrm{~kJ} \mathrm{~mol}^{-1}$. In the second stage between 420 and $480{ }^{\circ} \mathrm{C}$, the $\mathrm{Ph}$ ligand degrades as one maximum in the DTG curve at $470{ }^{\circ} \mathrm{C}$ with a mass loss of $37.45 \%$ (calc. $37.83 \%$ ). The third stage, which occurs in the temperature range of $690-730{ }^{\circ} \mathrm{C}$ with DTG peak observed at $710{ }^{\circ} \mathrm{C}$, corresponds to the decomposition of $\mathrm{A}^{4}$ ligand. The observed mass loss $(49.09 \%)$ is coinciding with the calculated value of $48.88 \%$. The overall mass losses are observed to be $90.95 \%$, which is in very good

Table 2 Kinetic parameters of complexes

\begin{tabular}{|c|c|c|c|c|c|c|c|}
\hline Complexes & TG range $/{ }^{\circ} \mathrm{C}$ & $E_{\mathrm{a}} / \mathrm{kJ} / \mathrm{mol}$ & $n$ & $A / \mathrm{s}^{-1}$ & $S^{*} / \mathrm{J} \mathrm{K} \mathrm{K}^{-1} / \mathrm{mol}$ & $H^{*} / \mathrm{kJ} / \mathrm{mol}$ & $G^{*} / \mathrm{kJ} / \mathrm{mol}$ \\
\hline \multirow[t]{3}{*}{$\mathrm{Cu}(\mathrm{II})-1$} & 180-190 & 3.16 & 1.00 & 0.01 & -102.23 & 0.43 & 41.51 \\
\hline & $315-335$ & 12.67 & 0.99 & 0.48 & -101.25 & 4.49 & 67.35 \\
\hline & $500-750$ & 22.25 & 0.99 & 31.55 & -95.21 & 22.36 & 98.11 \\
\hline \multirow[t]{3}{*}{$\mathrm{Cu}(\mathrm{II})-2$} & $180-200$ & 12.28 & 0.99 & 0.95 & -100.75 & 9.65 & 40.36 \\
\hline & $265-350$ & 15.25 & 0.99 & 5.32 & -101.32 & 9.75 & 63.33 \\
\hline & $360-420$ & 20.29 & 1.00 & 9.85 & -95.55 & 17.20 & 95.59 \\
\hline \multirow[t]{3}{*}{$\mathrm{Cu}(\mathrm{II})-3$} & $180-230$ & 5.25 & 0.98 & 0.17 & -101.09 & 0.88 & 29.57 \\
\hline & $500-600$ & 24.28 & 1.00 & 3.34 & -96.98 & 22.31 & 65.55 \\
\hline & $710-800$ & 42.19 & 1.00 & 5.81 & -97.13 & 30.37 & 107.67 \\
\hline \multirow[t]{3}{*}{$\mathrm{Cu}(\mathrm{II})-4$} & $160-220$ & 4.01 & 1.01 & 0.10 & -101.35 & 0.37 & 32.33 \\
\hline & $420-480$ & 31.55 & 0.98 & 33.55 & -94.44 & 21.44 & 75.57 \\
\hline & $690-730$ & 42.44 & 1.01 & 156.2 & -93.23 & 33.53 & 92.54 \\
\hline
\end{tabular}


agreement with the calculated value of $91.17 \%$. The final residue, estimated as $\mathrm{CuO}$, has the observed mass $8.68 \%$ as against the calculated value of $8.83 \%$.

Boltzman and Plank constants, respectively. There was no definite trend in the values of the entropy of activation. However, the negative value of the entropy of activation indicated that the activated complex has a more ordered structure than the reactants, and the reactions are slower than normal [39]. The kinetic paramerters, especially the energy of activation $\left(E_{\mathrm{a}}\right)$ values, are helpful in assigning the strength of complexes [40]. The calculated $E_{\mathrm{a}}$ values of the investigated complexes for the first dehydration step were in the range of 3.16-12.28 kJ mol${ }^{-1}$ (Table 2). Based on the $E_{\mathrm{a}}$ values, the thermal stabilities of complexes in the decreasing order are $\mathrm{Cu}(\mathrm{II})-2>\mathrm{Cu}(\mathrm{II})-3>\mathrm{Cu}(\mathrm{II})-4>\mathrm{Cu}(\mathrm{II})-1$.

Acknowledgements We express our gratitude to V. P. \& R. P. T. P. Science College, Chemistry Department, Sardar Patel University, Vallabh Vidyanagar, India for providing laboratory facilities.

Open Access This article is distributed under the terms of the Creative Commons Attribution Noncommercial License which permits any noncommercial use, distribution, and reproduction in any medium, provided the original author(s) and source are credited.

\section{References}

1. Sekerci M, Yakuphanogulu F. Thermalanalysis study of some transition metal complexes by TG and DSC methods. J Therm Anal Calorim. 2004;75:189-95.

2. Schultz D. Differential thermal analysis. Warszawa: PWN; 1974.

3. Magri AL, Magri AD, Balestrieri F, Cardarelli E, Ascenzo GD, Chiacchierini E. Thermal properties and spectroscopic characteristics of the complexes of pyrazine-2-carboxylic acid with divalent metal ions. Thermochim Acta. 1980;38(2):225-33.

4. Maslowke J, Malicka M. Thermal behavior of riboflavin. J Therm Anal. 1988;34(1):3-9.

5. Khalifa MEM, Todor DH. Study of thermal behaviour of some derivatives of triphenylamine, with a view to obtaining new stationary phases for Gas chromatography. J Therm Anal. 1982; 24(2):165-70.

6. Ciba J, Sycz J, Trzcionka J. Study of the thermal properties of derivatives of sulfonamides. J Therm Anal. 1983;26(1):145-50.

7. Chruscinska E, Maslowska J. Kinetics and mechanism of thermal decomposition of cadmium (II) complexes with substituted thioureas. J Therm Anal. 1988;32(5):1323-32.

8. Kumar S, Kaushir NK. Preparation, characterization and thermal studies on Bis-[N-(ethyl, m-tolyl)-dithiocarbamato] complexes of zinc (II), cadmium (II) and mercury (II). J Therm Anal. 1981; 21(1):3-7.

9. Feist M, Kunze R, Neubert D, Witke K, Kemnitz E. The thermal behaviour of triethylenediammonium salts. A combined investigation of (trienH $\mathrm{H}_{2}\left[\mathrm{CoCl}_{4}\right]$ and $\left(\operatorname{trienH_{2}}\right)_{2}\left[\left(\mathrm{FeCl}_{4}\right) 2\left(\mu-\mathrm{C}_{2} \mathrm{O}_{4}\right)\right]$. $2 \mathrm{H}_{2} \mathrm{O}$ using TG-MS, FT-IR, and Raman Spectroscopy. J Therm Anal Calorim. 1997;49(2):635-47.

10. Dranca L, Lupascu T, Sofransky V, Popa V, Vass M. Thermoanalytical study of salts of $3 \mathrm{~d}$ metals with D-tartaric acid. J Therm Anal Calorim. 1996;46(5):1403-12.
11. Marin ML, Jimenez A, Lopez J, Vilaplana J. Thermal analysis of ethylene (vinyl acetate), kinetic analysis of thermogravimetric data. J Therm Anal Calorim. 1996;47(1):247-58.

12. Elmasy MAA, Gaber A, Khater EMH. Thermal decomposition of $\mathrm{Ni}(\mathrm{II})$ and $\mathrm{Fe}(\mathrm{III})$ acetates and their mixture. J Therm Anal Calorim. 1996;47(3):757-63.

13. Rehman S, Arshad M, Masud K, Afzal R, Salma U. Pyrolytical characterization of transition metal complexes of cobalt, nickel, copper and zinc with ethylenediamine- $N, N^{\prime}$-diacetate. J Therm Anal Calorim. 2010;102:715-22.

14. Szunyogová E, Györyová K, Kovárová J, Juhászová E. Thermal behaviour of zinc(II) carboxylate complexes with methyl-3-pyridyl carbamate. J Therm Anal Calorim. 2003;71:967-76.

15. Olczak-Kobza M, Cichecka M. Zinc(II) (o-hydroxybenzaldoximates) complexes with mono- and bidentate ligands. J Therm Anal Calorim. 2001;66:379-86.

16. Soliman AA. Thermogravimetric and spectroscopic studies on cadmium complexes with two salicylidene thiophenol Schiff bases. J Therm Anal Calorim. 2001;63:221-31.

17. Mohamed GG, Nour El-Dien FA, El-Gamel NEA. Thermal behaviour of metal complexes of 6-(2-Pyridylazo)-3-acetamidophenol. J Therm Anal Calorim. 2002;67:135-46.

18. Sekerci M, Yakuphanoglu F. Thermal analysis study of some transition metal complexes by TG and DSC methods. J Therm Anal Calorim. 2004;75:189-95.

19. AbouEl-Enein SA. Polymeric and sandwich Schiff's bases complexes derived from 4,4-methylenedianiline. Characterization and thermal investigation. J Therm Anal Calorim. 2008;91(3): 929-36.

20. Kharadi GJ, Panchani SC, Patel KD. Coordination polymeric chain assemblies of some metal ions with BHQPP. Int J Polym Mater. 2010;59:60-72.

21. Kharadi GJ, Panchani SC, Patel KD. Studies on some coordination polymeric chain assemblies of metal ions with QM1 N. Int J Polym Mater. 2010;59:577-87.

22. Kharadi GJ, Patel JA, Dholakiya BZ. Antituberculosis, antifungal and thermal activity of mixed ligand transition metal complexes. Appl Organomet Chem. 2010;24(11):821-7.

23. Mohamed GG, Abd-Wahab ZH. Salisaldehyde-2-aminobenzimidazole schiff base complexes of $\mathrm{Fe}(\mathrm{III}), \mathrm{Co}(\mathrm{II}), \mathrm{Ni}(\mathrm{II}), \mathrm{Cu}(\mathrm{II})$, Zn(II) and Cd(II). J Therm Anal Calorim. 2003;73:347-59.

24. El-Boraey A. Structural and thermal studies of some aroylhydrazone Schiff's bases-transition metal complexes. J Therm Anal Calorim. 2005;81:339-46.

25. Kriza A, Loredana Dianu M, Andronescu C, Elena Rogozea A, Magdalena Musuc A. Synthesis, spectral and thermal studies of new copper (II) complexes with 1,2-di(imino-2aminomethylpyridil)ethane. J Therm Anal Calorim. 2010;100: 929-35.

26. Kharadi GJ, Patel KD. Novel copper(II) heterochelate: synthesis, structural features and fluorescence studies. Appl Organomet Chem. 2010;24:523-9.

27. Kharadi GJ, Patel KD. In vitro antimicrobial, thermal and spectral studies of mixed ligand $\mathrm{Cu}(\mathrm{II})$ heterochelates of clioquinol and coumarin derivatives. Appl Organomet Chem. 2010;24(4): $332-7$.

28. Perrin DD, Armarego WLF. Purification of laboratory chemicals. New York: Pergamon Press; 1988.

29. Kharadi GJ, Patel KD. Antibacterial, spectral and thermal aspects of drug based-Cu(II) mixed ligand complexes. Appl Organomet Chem. 2009;23(10):391-7.

30. Nakanishi K, Solomon PH. Infrared absorption spectroscopy. 2nd ed. San Francisco: Holden-Day, Inc.; 1977.

31. Karipcin F, Kabalcilar E. Spectroscopic and thermal studies on solid complexes of 4-(2-pyridylazo)resorcinol with some transition metals. Acta Chim Slov. 2007;54:242-7. 
32. Pang $\mathrm{W}$, Yang $\mathrm{H}, \mathrm{Wu} \mathrm{Z}$, Huang M, Hu J. LC-MS-MS in MRM mode for detection and structural identification of synthetic hypoglycemic drugs added illegally to 'natural' anti-diabetic herbal products. Chromatographia. 2009;70(9-10):1353-9.

33. Carballo R, Castineiras A, Covelo B, Garcia-Martinez E, Nicolas J, Vazquez-Lopez EM. Solid state coordination chemistry of mononuclear mixed-ligand complexes of $\mathrm{Ni}(\mathrm{II}), \mathrm{Cu}$ (II) and $\mathrm{Zn}$ (II) with a-hydroxycarboxylic acids and imidazole. Polyhedron. 2004;23:1505-18.

34. Iskander MF, EL-Sayed L, Salem NMH, Werner R, Haase W. Synthesis, characterization and magnetochemical studies of dicopper(II) complexes derived from bis( $\mathrm{N}$-salicylidene)dicarboxylic acid dihydrazides. J Coord Chem. 2005;58:125-39.

35. Mendoza-Diaz G, Martineza-Auguilera LMR, Perez-Alonso R, Solans X, Moreno-Esparza R. Synthesis and characterization of mixed ligand complexes of copper with nalidixic acid and $(\mathrm{N}-\mathrm{N})$ donors. Crystal structure of $\left[\mathrm{Cu}(\mathrm{Phen})(\mathrm{Nal})-\left(\mathrm{H}_{2} \mathrm{O}\right)\right] \mathrm{NO}_{3} \cdot 3 \mathrm{H}_{2} \mathrm{O}$. Inorg Chim Acta. 1987;138:41-7.

36. Melnik M. Mono-, bi-, tetra- and polynuclear copper(II) halogenocarboxylates. Coord Chem Rev. 1981;36(1):1-44.

37. Figgis BN, Lewis J. In: Lewis J, Wilkins RG, editors. Modern coordination chemistry: principles and methods. New York: Interscience; 1960. p. 400.

38. Kharadi GJ, Patel KD. Synthesis, spectroscopic, thermal and biological aspect of mixed ligand copper(II) complexes. J Therm Anal Calorim. 2009;96:1019-28.

39. Aravindakshan KK, Muraleedharan K. Thermal decomposition kinetics of 2-furaldehyde thiosemicarbazone complexes of cadmium(II) and mercury(II). Thermochim Acta. 1989;155:247-53.

40. Frost AA, Pearson RG. Kinetics and mechanism. New York: John Wiley; 1961. 